\title{
UMA COMUNIDADE DE CORTES: A GLOBALIZAÇÃO E A FUNÇÃO JUDICIAL
}

\author{
Gláucio Maciel Gonçalves ${ }^{1}$ \\ Érico Andrade ${ }^{2}$ \\ Alex Lamy de Gouvêa ${ }^{3}$
}

Resumo: este artigo tem como objetivo apontar aspectos da cooperação judiciária transnacional entre juízes, como a cada vez mais global jurisprudência constitucional, a crescente interação judicial e o desenvolvimento de uma doutrina distinta do judicial comity, dentre outros que, juntos, representam a construção gradual de sistema legal global no qual os juízes começam a se reconhecer como participantes de um empreendimento judicial comum e membros de uma profissão que transcende as fronteiras nacionais, segundo SLAUGHTER (2004) e outros autores brasileiros e estrangeiros.

Palavras-chave: comunidade de cortes; cooperação judicial; litígios transnacionais; sistema legal global; função judicial

\section{A COMMUNITY OF COURTS: GLOBALIZATION AND JUDICIAL TASK}

Abstract: this paper aims to appoint aspects of transnational judicial cooperation between judges, such as the increasingly global constitutional jurisprudence, the growing judicial interaction and the development of a distint doctrine of judicial comity, among others that, together, represent the gradual construction of a global legal system into which judges start to recognise themselves as participants in a common judicial enterprise, members of a profession that transcends national borders, according to SLAUGHTER (2004) and others authors in Brazil and abroad.

Key-words: Community of courts; judicial cooperation; transnational litigation; global legal system; judicial task.

\section{Introdução}

\footnotetext{
1 Gláucio Maciel Gonçalves é professor associado da Universidade Federal de Minas Gerais (UFMG), membro do corpo permanente da pós-graduação e juiz federal em Belo Horizonte-MG. Mestre e Doutor em Direito pela UFMG, fez estudos de pós-doutoramento na Albert-Ludwigs-Universität, em Freiburg, Alemanha (2015/2016); e-mail: gfmg@ufmg.br.

2 Érico Andrade é professor adjunto da UFMG, membro do corpo permanente da pós-graduação e advogado em Belo Horizonte-MG. Doutor em Direito Processual Civil e Mestre em Direito Administrativo pela UFMG, fez estudos de pós-doutoramento na Università degli Studi di Milano (2019/2020); e-mail: ericoandrade@ufmg.br.

3 Alex Lamy de Gouvêa é bacharel, mestre e doutorando em Direito pela Faculdade de Direito da Universidade Federal de Minas Gerais (UFMG) e juiz federal substituto em Sete Lagoas-MG; e-mail: lamy.gouvea@yahoo.com.br.
} 
O exercício da função judicial cada vez menos se confina à competência territorial do magistrado; ao mesmo tempo, cada vez mais os juízes têm se articulado ao redor de problemas, casos e formações em comum. Assim sendo, "se partimos do princípio que o direito em geral, ou pelo menos em muitas áreas do direito (...) têm sido, estão sendo ou serão globalizadas, então se torna significativo discutir um tema que trata da 'globalização da justiça processual"” (TARUFFO, 2017, p. 13).

Em The Court and the World, StEPHEN BREYer (2015, p. 7), Associate Justice da Suprema Corte americana, baseado na sua experiência judicante, ilustra e explica o que tem visto e por que acredita haver um crescimento constante da necessidade de as cortes desenvolverem um entendimento sobre e trabalhar relações com outras cortes e instituições legais estrangeiras.

Casos como o de um tailandês, estudando nos EUA, que constatara serem os livros muito caros no território americano, decidindo comprá-los na Tailândia (a um preço evidentemente mais em conta) e os revender para os estudantes americanos, e a discussão sobre a constitucionalidade de trechos do Foreign Intelligence Service Act (FISA), na seção que permite ao governo americano - em atenção à segurança nacional - ouvir eletronicamente certas conversas de estrangeiros fora do território americano, ambos previstos para debates e decisão em uma semana de trabalho na Suprema Corte, chamaram a atenção do magistrado. Isso, em razão do número crescente de processos envolvendo estrangeiros ou atividades no exterior, comércio internacional ou ameaças externas à segurança nacional que têm chegado ao judiciário americano, evidenciando a cada vez maior presença do elemento estrangeiro nos processos em curso e, por consequência, da transnacionalidade, implicando "problemas [que] exigirão dos judiciários de diferentes nações a condução separada, porém, colaborativa [dos casos]" (BREYER, 2015, p. 6).

Em sentido geral, esclarece Michele TARUFFO (2017, p. 12-13), transnacional "refere-se a qualquer tipo de litígio que surge entre as partes (cidadãos, empresas, Estados nacionais, organizações internacionais, empresas multinacionais e assim por diante) que 'pertencem' a diferentes jurisdições nacionais", relacionando o tema diretamente com a “administração da justiça em nível transnacional”, como se dá em cada vez maior número nas disputas trabalhistas (decorrência da terceirização e deslocamento da mão-de-obra pelo mundo), relativas ao meio ambiente e sobre a propriedade intelectual (em face da circulação quase irrestrita de mercadorias e serviços). Como afirmam JULIE AllaRd e ANTOINE 
GARAPON (2006, p. 7), “o direito tornou-se um bem intercambiável. Transpõe as fronteiras como se fosse um produto de exportação. Passa de uma esfera nacional para outra, por vezes infiltrando-se sem visto de entrada".

ANNE-MARIE Slaughter (2004, p. 65) afirma que a globalização, pensada normalmente em termos de empresas e mercados globais, também é um fenômeno que passa a alcançar os juízes, os quais conversam entre si, trocam opiniões, reúnem-se em seminários, organizações ou associações ou cooperam diretamente, "negociando um com o outro o resultado de casos específicos”. ALLARD e GARAPON (2006, p. 14) chegam mesmo a afirmar que "durante muito tempo limitados à interpretação rigorosa do direito, os juízes são hoje provavelmente os agentes mais activos da sua mundialização e, por conseguinte, os engenheiros de sua transformação”. De igual modo pensa NiCOLA PICARDI (2012, p. 1156), para quem, na ausência de regulamentação das relações entre sistemas diferentes, os juízes assumem a tarefa de resolver um tráfego legal, que se torna mais denso, inextricável e complexo a cada dia, assumindo o papel não mais de "receptores de regras, mas os próprios reguladores dessas relações”. Assim, transformação e globalização se tornam cada vez mais presentes no exercício da jurisdição, ensejando que a coordenação entre elas "se tornará cada vez mais necessária para o suave funcionamento de nossa economia e de nossas diversas instituições" (BREYER, 2015, p. 4).

O maior fluxo de informações, experiências, casos de cooperação direta e específica entre juízes reflete em vários aspectos do exercício da função judicial, como este texto pretende esboçar em linhas gerais.

\section{Um empreendimento judicial global}

Um dos resultados da judicial globalization é o aumento global da jurisprudência constitucional, com cortes referenciando e citando umas às outras em casos de repercussão: pena de morte, aborto, casamento gay, liberdade de expressão etc. Para SLAUGHTER (2004, p. 66-68), os juízes não mais estão em postura de recepção passiva de decisões estrangeiras, mas em um ativo e progressivo diálogo, asseverando que o momento vivido é o de construção de um sistema legal global (global legal system), caracterizado do seguinte modo: diferentemente do que se imaginou, ou seja, um sistema global hierarquizado, com uma Suprema Corte Internacional, resolvendo os casos, o sistema legal global se forma mais 
desorganizado e mais complexo, com redes de trabalho horizontais e verticais, composta por juízes nacionais e internacionais, construídas com base na atuação em uma área comum ou em uma particular região do mundo. Os juízes componentes destas redes de trabalho as constituem impelidos por questões relativas à política judiciária, à carga de trabalho e aos novos impactos de regras internacionais sobre os litigantes nacionais.

A análise da jurisprudência de uma corte para julgamento de caso pertencente a outra, de distintos países, iniciada a partir do controle de convencionalidade que passou a existir com a formação de blocos de nações e, normalmente, relacionada a direitos humanos ou a comércio internacional, expandiu-se para outros campos do saber jurídico. O juiz atual está inserido em um sistema de justiça em que é indispensável o contato com seu colega estrangeiro, seja para conhecer particularidades do funcionamento da outra justiça, seja para se inteirar das fontes do próprio direito que será aplicado por ele no caso em exame.

Em sentido próximo, Allard e GARAPON (2006, p. 35) afirmam que "a mundialização da justiça funciona (...) como um princípio de estabelecimentos de relações nos termos do qual nenhum tribunal poderá permanecer indiferente aos seus homólogos, sem que para tal, intervenham quaisquer vínculos ou instâncias físicas de cooperação”. Deste modo, o "novo comércio entre juízes" é "um fórum informal de intercâmbios situado, na maior parte das vezes, à margem dos mecanismos institucionais".

Aquilo que estes juízes compartilham nestas redes, acima de tudo, é o reconhecimento, uns nos outros, como participantes de um empreendimento judicial em comum. Estes juízes se veem e veem os outros juízes não somente como servidores ou representantes de um governo em particular, mas como colegas de uma profissão que transcende fronteiras nacionais, encarando os mesmos problemas substanciais e institucionais, aprendendo com o raciocínio e a experiência dos colegas e cooperando diretamente para resolver casos específicos, concebendo-se como capazes de ações independentes nos domínios internacional e doméstico (Slaughter, 2004, p. 68) ${ }^{4}$. Allard e Garapon (2006, p. 36) afirmam ser a "descontinuidade radical entre o espaço judicial clássico e este novo espaço de comunicação, que faz abalar a distinção entre nacional/internacional e

\footnotetext{
$4 \quad$ No mesmo sentido, MARISTELA BASSO (2009, p. 248): "Pedidos e solicitações feitos por autoridades judiciárias de um Estado para o juiz doméstico têm como base a ideia de que a responsabilidade pelo gerenciamento da justiça entre Estados é uma tarefa comum no plano internacional, compartilhada entre Estados, e dependem justamente da cooperação entre eles para que os tribunais possam adequadamente assegurar o interesse das partes e a proteção dos direitos que lhes sejam atribuídos".
} 
supranacional”. Para estes autores, a mundialização já se tornou numa dimensão do direito interno, conferindo poder aos próprios sistemas, "que não desaparecem em nome de uma ordem mundial superior".

O sistema criado, ao fim, é mais bem descrito como comunidade de cortes (community of courts) do que como uma hierarquia centralizada (SLAUGHTER, 2004, p. 68) ${ }^{5}$. Alguns o nomeiam por "sociedade de tribunais", sendo que "esses intercâmbios acarretam um elo social, sem que este último seja vinculado a uma pirâmide de normas ou a uma ordem política determinada", caracterizando este espaço como "não hierárquico e policêntrico", semelhante a uma rede, na qual a "vontade do legislador perde o seu papel organizador e os sistemas jurídicos enredam-se num emaranhado". "O mecanismo daí resultante é estritamente informal", sendo que "a ausência de hierarquia e a acefalia constituem, elas próprias, as condições de seu funcionamento" (ALLARD; GARAPON, 2006, p. 36).

\section{A formação de redes judiciais e a emergente "comunidades de cortes"}

O fenômeno de criação de redes está espraiado por todas as áreas do mundo atual: comunicação, inteligência, trabalho, economia, criminalidade organizada ${ }^{6}$, justiça... Para MANUEl CAStells (2018, p. 11-12), autor de A sociedade em rede, as redes constituem uma nova estrutura social - a sociedade em rede - "constituída em redes em todas as dimensões fundamentais da organização e prática social". Estas redes, uma vez que "não param nas fronteiras do Estado-Nação", prenunciam "uma nova forma de globalização característica de nosso tempo". "Tempos conturbados", diz o autor, porquanto tempos de "agonia e incerteza",

$5 \quad$ "What these judges share above all is the recognition of one another as participants in a common judicial enterprise. They see each other not only as servants and representatives of a particular government or polity, but also as fellow members of a profession that transcends national borders. They face common substantive and institutional problems; they learn from one another's experience and reasoning. They cooperate directly to resolve specific disputes. And they conceive of themselves as capable of independent action in both the international and domestic realms (...) The system these judges are creating is better described as a community of courts than as a centralized hierarchy" (SLAUGHTER, 2004, p. 68). Para outra designação do fenômeno: "A literatura especializada fala alternativamente de 'diálogo entre juízes', de 'mundialização judicial' ou ainda de 'auditório global'. Pelo nosso lado, optaremos por nos referir a 'comércio entre juízes'. A expressão apresenta o mérito de remeter para as duas facetas da mundialização do direito: é simultaneamente uma rede de trocas, intercâmbios, e uma forma de sociabilidade nascida do desejo de estabelecer relações sólidas, corteses e serenas, uma 'dependência recíproca de homens', para retomar os termos de Diderot na Encyclopédie" (ALLARD; GARAPON, 2006, p. 9).

6 "A economia criminosa global (que corresponde a 5\% do PIB mundial) está construída sobre as suas próprias redes específicas, com nós que geralmente não coincidem com os das finanças ou da inovação tecnológica". (CASTELLS, 2018, p. 30). 
com a "crescente incapacidade das instituições políticas baseadas no Estado-nação em lidar com problemas globais e as demandas locais".

CASTELLS (2018, p. 35) afirma que as redes se tornaram a forma de organização predominante de todos os campos da atividade humana. A globalização se intensificou e se diversificou. As tecnologias de comunicação construíram a virtualidade como uma dimensão fundamental de nossa sociedade. O espaço dos fluxos sobrepujou a lógica dos espaços dos lugares, prenunciando uma arquitetura espacial global de megacidades interconectadas enquanto as pessoas continuam a achar significado em lugares e a criar suas próprias redes no espaço dos fluxos.

No plano das organizações, CASTELlS (2018, p. 124) observa que "o paradigma da tecnologia de informação é baseado na flexibilidade" e, em assim sendo, "não apenas os processos são reversíveis, mas organizações e instituições podem ser modificadas e até mesmo fundamentalmente alteradas, pela reorganização de seus componentes". Esta característica possibilitou "inverter as regras sem destruir a organização, porque a base material da organização pode ser reprogramada e reaparelhada".

Em certa medida, estão neste mesmo sentido as análises das ideias de SLAUGHTER, feitas por ALLARD e GARAPON (2006, passim), de acordo com os quais, para a autora americana, as redes de governo (government networks) constituem "uma nova configuração no plano mundial". A mundialização implica a "desarticulação dos três poderes (...) para inscrevê-los num[a] nova configuração no plano mundial", de tal modo que "cada um desses três poderes seria dissociado da soberania nacional para se associar aos seus homólogos estrangeiros. Nesta perspectiva, o comércio entre juízes procederia, por conseguinte, de uma extensão do poder judicial para além das fronteiras”.

Na visão de TARUFFO (2017, p. 16-17), esta “globalização da justiça processual pode ser considerada como um fator poderoso de igualdade na medida em que pode garantir acesso igual à proteção judicial dos direitos fundamentais de todos, principalmente, dos fracos”. Resgatando as lições de LUIGI FERRAJOLI, TARUFFO recorda que a jurisdição é "a garantia fundamental de todos os direitos, mas especialmente dos direitos fundamentais que são principalmente importantes para os mais fracos: nenhum direito (...) realmente existe se não pode ser reivindicado e protegido por meios jurisdicionais".

De igual modo, ao abordar os princípios do acesso à justiça global e da proibição de denegação da justiça, destaca FABRício POLIDO (2013, p. 41) a tendência da literatura jurídica 
especializada em examinar a "minimização do absolutismo da jurisdição dos Estados, como expressão da soberania", ao mesmo tempo em que busca "confirmar a tese de que os órgãos jurisdicionais devem atender aos interesses dos indivíduos e grupos em suas demandas concretas, sobretudo enquanto questões de acesso à justiça, denegação de justiça e autonomia da vontade estiverem em consideração". Para Polido, referenciando AlEX MiLls, "trata-se (...) do crescente entendimento da jurisdição (poder-julgar) como sendo reflexo de direitos fundamentais, muito além do que simples expressão de direitos do Estado (...)"

No tocante à centralidade da figura do juiz neste cenário, interessante a leitura do Étude Annuelle, edição de 2017, da Cour de Cassation francesa, com o título Le juge et la mondialisation dans la jurisprudence de la Cour de Cassation.

Para o estudo, a mundialização ${ }^{8}$ afeta diretamente o papel do juiz nacional. Com efeito, o juiz é portador de soberania, sendo fundamentalmente ligado a um território, em razão de sua competência; território este que se define por seus valores, regras e direito ${ }^{9}$. A mundialização, entrementes, "joga” com as fronteiras nacionais. Assim, num primeiro ponto de vista, os dois termos - juiz nacional e mundialização - poderiam parecer inconciliáveis: o juiz nacional, ligado a um Estado, a um território; a mundialização, por seu turno, colocando

No mesmo sentido: "Entender a cooperação entre Poderes Judiciários como um princípio também representa uma nova maneira de situar o DIPr como um sistema protetivo da pessoa humana e não apenas como ferramenta disciplinadora do relacionamento dos Estados. (...) O Processo Civil Internacional deve ser analisado por uma ótica que dê prevalência à proteção da pessoa humana e sua dignidade, como objetivo maior do sistema" (ARAÚJO, 2019, p. 161).

$8 \quad$ O estudo esclarece que o fenômeno mundialização pode ser definido como "une mise en rapport généralisée des espaces économiques, sociaux et culturels", résultant d'une multiplication sans précédent des échanges et de réseaux entre tous les êtres humains. Elle conduit à la création d'un espace mondial interdépendant. (...) Enfin, la mondialisation, telle qu'entendue ici, se confond sans doute avec la globalisation. Pour autant, le terme de mondialisation doit être préféré pour plusiers raisons. Premièrement, l'adjectif "global" et le substantif "globalisation" auquel il donne naissance ont une coloration américaine. Deuxièmement, même si les termes sont étymologiquement très poches, l'adjectif "global" comporte une signification qui peut permettre de fair le départ entre les deux notions. Il designe ce "qui est considere en bloc, dans sa totalité, qui s'applique à un ensemble sans considérer le détail". En ce sens, la globalisation peut être perçue comme le stade ultime de la mondialisation. Pour l'heure, la mondialisation n'est pas la globalisation, car la mise en relation généralisée qu'elle implique n'a pas encore supprimé les États et les territoires. Enfin, et troisièmement, le terme de mondialisation est marqué d'un ancrage historique: la mondialisation est un processus pluriséculaire qui se poursuit”. (COUR DE CASSATION, 2017, p. 9).

É neste sentido a lição da doutrina clássica: "O Estado, personalidade originária de direito internacional público, ostenta três elementos conjugados: uma base territorial, uma comunidade humana estabelecida sobre essa área, e uma forma de governo não subordinada a qualquer autoridade exterior. (...) Sobre o seu território o Estado exerce jurisdição (termo preferido em doutrina anglo-saxônia), o que vale dizer que detém uma série de competências para atuar com autoridade (expressão mais ao gosto dos autores da escola francesa). (...) Sobre o território assim entendido, o Estado soberano tem jurisdição geral e exclusiva. A generalidade da jurisdição significa que o Estado exerce no seu domínio territorial todas as competências de ordem legislativa, administrativa e jurisdicional. A exclusividades significa que, no exercício de tais competências, o Estado local não enfrenta a concorrência de qualquer outra soberania" (REZEK, 2014, p. 199-200). 
em xeque as fronteiras. Mas a impressão é errada, pois o juiz nacional constitui "exatamente o ponto de encontro entre o direito e a mundialização. É o juiz que, a cada dia, é confrontado com a mundialização concreta dos litígios e com a mundialização do direito", motivo pelo qual o estudo interroga "sobre o modo pelo qual a mundialização modifica, perturba, mas também enriquece o papel do juiz nacional", que está sendo repensado e se encontra em transformação (COUR DE CASSATION, 2017, p. 11-12).

Não se pode descurar, todavia, que um dos princípios organizadores da emergente “comunidade de cortes", tais como descritos por SLAUGHTER (2004, p. 68), é a ressignificação do clássico check and balances tanto no plano vertical quanto no horizontal. Assim, na mais desenvolvida rede de trabalhos judiciais - a comunidade europeia -, nem os tribunais nacionais nem os internacionais detêm a supremacia nas decisões. No plano horizontal, as cortes nacionais seguem conscientes de seus papéis e prerrogativas como cortes de Estados independentes e interdependentes, mesmo reconhecendo a necessidade de cooperação e deferência com as demais cortes.

Em acréscimo, merece relevo que a mundialização dialoga diretamente com o tempo nos processos. Como observou GLÁUCIO MACIEL GonÇALVES (2011, p. 286):

[em razão da] constatação de que o tempo usual era insuficiente para o propósito de
existência da função jurisdicional estatal em alguns casos, a doutrina sustentou a
necessidade de se criarem procedimentos especiais ou, ao menos, técnicas
processuais específicas para atender a necessidades únicas do direito material
tutelado, o que foi reconhecido pelo legislador.

Neste contexto, a proclamação da garantia fundamental à razoável duração do processo e aos meios que garantam a celeridade de sua tramitação, expressa no art. $5^{\circ}$, LXXVIII, da Constituição, acrescentado pela Emenda 45/04 - que decorre do devido processo legal material - em face de sua imediata aplicação (art. $5^{\circ}, \S 1^{\circ}$, da Constituição), exige a utilização ótima dos instrumentos previstos nas leis processuais, com as atenções voltadas para a complexa realidade do país e do mundo.

No mesmo sentido, destacou o Étude Annuelle da Cour de Cassation (2017, p. 8) que “os temas do tempo e da mundialização são, além disso, ligados. A mundialização provocando uma aceleração do tempo, assim que uma contração do tempo".

Em verdade, observa CASTELLS (2018, p. 32-34, passim), “o processo de globalização acelerou o ritmo de produção, gestão e distribuição de bens e serviços em todo o planeta, medindo produtividade e concorrência por meio da redução do tempo ao menor nível possível". Para o espanhol, o tempo do relógio está sendo substituído pelo que conceituou de 
tempo atemporal, que "não se trata de uma única forma de tempo, mas é o tempo do poder na sociedade em rede". O tempo atemporal "acontece quando há uma perturbação sistêmica na ordem sequencial das práticas sociais desempenhadas no âmbito de um determinado contexto, como a sociedade em rede". As organizações continuam a utilizar o tempo do relógio ao mesmo tempo em que as pessoas flexibilizam o seu, encontrando-se em diferentes regimes temporais, com a "realização simultânea de múltiplas tarefas por meio da aceleração proporcionada pela tecnologia", em uma prática social "cujo objetivo é negar a sequência para nos instalar na simultaneidade perene e na ubiquidade simultânea”.

O fenômeno que vem se observando, portanto, é a tentativa de abertura de novas veredas de acesso à justiça no séc. XXI, assim entendida como o acesso à jurisdição civil mais efetiva, quando constantes do processo elementos com aspectos transnacionais capazes, por si sós, de provocar quer o surgimento de consideráveis dificuldades no cumprimento dos provimentos jurisdicionais internacionais ou supracionais (dimensão espacial ou da soberania de cada Estado) quer maior delonga (dimensão temporal ou do tempo das instituições tradicionais) ou mesmo a completa inviabilização no alcance do bem da vida pretendido (decorrente dos custos, por exemplo).

Não por outro motivo, pontuaram ALLARD e GARAPON (2006, p. 38) que a primeira dimensão do comércio entre juízes é funcionalista: "é necessário acompanhar as evoluções do mundo e adoptar um direito mais móvel quando os objetos também o são", uma vez que "o direito acompanha o que é transfronteiriço por natureza". Desse modo, no aspecto econômico, “tal intensificação do comércio entre juízes advém da necessidade de reduzir os custos de transacção e de garantir a segurança dos intercâmbios através de uma linguagem comum, de símbolos e de instrumentos operativos".

Humberto Theodoro Júnior, Dierle nunes, Alexandre Bahia e Flávio QUINAUD (2016, p. 132) destacam que “o judiciário, a partir do processo constitucional, passa a ocupar papel de destaque na efetivação desses direitos. Sua função é não apenas de aplicação da norma jurídica, mas de materialização desta", e prosseguem dizendo que é de muita importância a busca por formas de viabilizar a cooperação judiciária, com o propósito de diminuir gastos com os atos judiciais e de acelerá-los, o que concretizará os princípios da celeridade e da eficiência.

Além do mais, tal preocupação, que ganha força na atualidade, indica que o Judiciário também - e não apenas a sociedade - tem que assumir uma postura dialógica, uma 
vez que a construção de canais internos de comunicação só tem a representar um ganho para toda a sociedade brasileira (THEODORO et alli, 2016, p. 132).

\section{Diferentes interações judiciais no espaço global}

Com estas premissas, na linha da exposição de SLAUGHTER (2004, p. 68), diferentes categorias de interações judiciais podem ser pontuadas, em um esboço geral: A fertilização cruzada constitucional (constitutional cross-fertilization), a construção de uma comunidade global de direitos humanos, litígios privados internacionais e encontros pessoais entre juízes ao redor do mundo.

Tomados em conjunto, estas categorias revelam um mundo no qual cortes travam interações quase-autônomas com outras cortes, criando redes de trabalho, de informação e de cumprimento das decisões internacionais ou transnacionais, favorecendo o surgimento de redes de harmonização. São interações que permitem o alcance de necessidades especiais e particularizadas embora ao mesmo tempo acabem revelando padrões maiores e princípios, tendo por resultado o alvorecer de um sistema legal global.

\subsection{A fertilização cruzada constitucional}

A primeira das categorias - a fertilização cruzada constitucional (constitutional cross-fertilization) - decorre diretamente da globalização, especialmente do acesso instantâneo, em muitos casos, às decisões tomadas pelas cortes usualmente referenciadas ao redor do mundo.

BREYER (2015, p. 240) constata pragmaticamente que quando os juízes ao redor do mundo assumem a responsabilidade do controle de constitucionalidade das leis, eles se encontram em face de problemas similares. Assim,

[S]e alguém com um trabalho praticamente igual ao meu, em face de um problema legal praticamente igual ao que confronto, interpretando um documento que se parece com aquele que eu analiso, escreveu uma opinião legal sobre o mesmo tema, por que não ler o que o juiz disse? Eu posso aprender a partir dele, mesmo que eu acabe por não concordar.

SLAUGHTER (2004, 70-71) observa que juízes das supremas cortes - juízes com jurisdição constitucional - estão em um crescente diálogo com os seus homólogos ao redor do mundo, diálogo que se dá por meio de citações recíprocas e cada vez mais frequentes 
interações diretas, muitas vezes por meio eletrônico. Os resultados desta fertilização cruzada são o surgimento de uma jurisprudência global a respeito de determinados temas e o incremento da qualidade das decisões nacionais, ora em razão da importação de ideias, ora pela resistência intestina às ideias estrangeiras. Citando a Justice SANDRA O'CoNNOR, da Suprema Corte americana, sintetiza a autora a causa de tais interações em uma frase: "atualmente nenhuma instituição do governo pode ignorar o resto do mundo".

Indo além, o Étude Annuelle da Cour de Cassation (2017, p. 11) generaliza as conclusões para todos os juízes, afirmando, a respeito do juiz nacional, que este deve ser "maleável, mas também firme. Maleável porque o fenômeno da globalização existe e o juiz deve enfrentá-lo, adaptar-se a ele, mas também contribuir para ele; firme por que certos valores devem ser defendidos e o juiz é o melhor garante deles".

Cross-fertilization, destaque-se, é diferente de simples transporte (transplantion). Esclarece a juíza da Suprema Corte canadense L'HeureuX-Dubé que o "processo de influência internacional mudou de recepção para diálogo. Os juízes não mais simplesmente recebem os casos de outras jurisdições e, então, os aplica ou modifica para a sua própria jurisdição" (apud Slaughter, 2004, p. 74). Como anotam Allard e GARAPON (2006, p. 12), "ao incentivarem os juízes a servirem-se dos argumentos de decisões estrangeiras, a discutirem a eficácia de diferentes soluções possíveis ou a avaliarem permanentemente os sistemas jurídicos", ocorrem não só uma modificação no estilo de se exercer a função judicante como, de mesmo modo, verifica-se um aumento na "racionalidade das decisões de justiça”.

Para Slaughter (2004, p. 74-75), a consciência da fertilização cruzada constitucional em uma escala global cria incentivos para emprestar e tomar emprestado decisões.

Malgrado divergências a respeito do denominado transjudicialismo ${ }^{10}$, para juízes que o adotam como prática, o olhar para as decisões, literatura ou casos em debate no exterior favorece a realização de um trabalho mais elaborado no plano doméstico, ao permitir a abordagem dos litígios sob suas responsabilidades de um modo mais criativo e claro. Para ALlARD e GARAPON (2006, p. 24), a referência a decisões estrangeiras tem diversas finalidades: encontrar soluções ou argumentos lógicos, inicialmente, "mas, para resolverem 10 Cf.: BREYER. The court and the world, p. 243 e ss.; SLAUGHTER. A new world order, p. 74 e ss.
WALDRON. "Partly Laws Common to All Mankind” (...), p. 24-27, passim. 
estes casos de difícil decisão, os juízes procuram igualmente uma base, uma garantia jurídica. À fertilização recíproca, vem, portanto, juntar-se uma busca de legitimidade”.

O transjudicialismo acaba por permitir, ao cabo, uma convergência de decisões, de modo a envolver algo ainda mais profundo: a emergência de uma jurisprudência global a respeito de determinados temas; e, nesta emergência, dado que as questões normalmente intercambiadas guardam estreita pertinência com direitos humanos fundamentais, surge uma práxis judicial rumo à globalização dos direitos humanos ou, em outras palavras, um movimento em direção a uma comunidade global de direitos humanos (toward a global community of human rights law). O Étude Annuelle da Cour de Cassation (2017, p. 14) por exemplo, expressamente reconhece que "a mundialização, por contribuir para o fortalecimento dos direitos fundamentais, constitui, graças à ação do juiz, uma fonte de progresso do direito francês".

TARUFFO (2017, p. 15) destaca a "generalização da sensibilidade em relação ao reconhecimento e aplicação dos direitos fundamentais" como um "aspecto extremamente significativo da globalização cultural e jurídica”, constatando cuidar-se de decorrência do fenômeno "globalização judicial", entendido como tendência dos tribunais de buscar como fontes argumentativas e paradigmáticas decisões de cortes congêneres, internacionais ou supranacionais ${ }^{11}$. Para TARUFFO (2017, p. 15), com esta postura, "estes tribunais vão muito além dos limites do direito e da jurisdição nacionais e referem-se ao que parece ser um 'núcleo comum e - espera-se - global' dos direitos fundamentais".

Deste modo, afirma SABINo CASSESE (2009, p. 139) que os juízes são chamados ao desempenho de um duplo papel constitucional na atual arena global: definir (verticalmente) as relações entre as diferentes ordens legais e integrar (horizontalmente) os diferentes sistemas regulatórios setoriais.

Neste sentido, JEREMY WALDRON (2012, p. 3) , afirma que às vezes é apropriado que os tribunais façam uso de materiais legais estrangeiros. "Para sustentar esse argumento,

\footnotetext{
$11 \quad$ No mesmo sentido: “Até muito recentemente confinados ao território nacional, os juízes passam, de agora em diante, a estabelecer entre eles, e através das fronteiras, relações cada vez mais sólidas e confiantes. Estas relações podem tomar as formas mais diversas: referência a julgamentos estrangeiros em decisões de âmbito nacional, intercâmbio de argumentos, formações em comum, diálogo entre tribunais, criação de associações transnacionais, de clubes ou sindicados de juízes, capitalizações informais de jurisprudência, etc. É neste contexto que nos últimos anos, relativamente a matérias tão sensíveis como a homossexualidade, a eutanásia ou o financiamento das campanhas eleitorais, pudemos ver juízes europeus socorrerem-se de argumentos dos seus homólogos americanos e juízes americanos basearem-se em demonstrações dos seus colegas europeus". (ALLARD; GARAPON, 2006, p. 8-9).
} 
pretendo expor um entendimento da lei que não é tão firmemente vinculado a sociedades particulares como a posição óbvia parece pressupor”. Com esta premissa, avança para sustentar que toda sociedade é governada parcialmente por suas próprias leis e parcialmente por leis comuns à humanidade. Na sequência, argumenta que correntes convergentes de leis, disposições constitucionais e precedentes estrangeiros às vezes se somam a um corpo de leis que tem a sua própria reivindicação: a lei das nações, ou ius gentium, que se aplica simplesmente como lei e não como a lei de qualquer jurisdição específica.

\subsection{O judicial comity}

Mas não só no campo dos direitos humanos a cooperação internacional entre juízes se revela crescente... Com efeito, se no tocante aos direitos humanos, as questões que se colocam são as relativas à adoção da autoridade persuasiva dos precedentes estrangeiros, à soberania nacional e ao clamor internacional por maior e melhor proteção dos direitos humanos fundamentais, no plano do litígio transnacional comum, as questões práticas relevantes são as relativas à competência para processar e julgar os casos, ao judicial comity e aos acordos entre juízes (judicial negotiation), dentre outras.

Em verdade, mesmo se as fronteiras tenham sido ao longo da história quase sempre porosas, elas são, atualmente, mais que porosas. São tranquilamente transpostas ${ }^{12}$. Como observa SLAUGHTER (2004, p. 85), quando produtos têm os seus componentes fabricados em três diferentes países, são montados em um quarto e vendidos e distribuídos em cinco ou seis outros, o número potencial de competências territoriais nacionais para resolver as disputas decorrentes se multiplica rapidamente. Ante ao desafio da transnacionalidade, o diálogo entre cortes se torna indispensável, provocando o surgimento de sistema global legal, formado pelas cortes nacionais trabalhando juntas ao redor do mundo.

Por outro lado, SLAughter (2004, p. 85-86) pontua que as relações dentro deste sistema não são sempre harmônicas. Pelo contrário, exatamente em razão do contato direto entre juízes, ora surgem oportunidades para cooperação, ora para conflitos. A combinação de

12 "Même si les frontières ont toujours été franchies, elles sont aujourd'hui allégrement dépassés. L'homme moderne n'est plus assigné à résidence: il devient um citoyen du monde")(COUR DE CASSATION, 2017, p. 8). No âmbito da União Europeia, a livre circulação de mercadorias, pessoas e serviços são fundamentais. "As its heart lay the free movement of goods, persons, services, and capital. These are known as the four freedoms and they remain fundamental to the EU’.' (ARNULL, 2017, p. 6). 
colaboração e conflito é a marca de um movimento a partir do comity clássico para um sistema integrado. Enquanto o comity clássico encontra-se ancorado na presunção de um mundo de soberanias, a implicar cortesia internacional e deferência entre Estados, a presunção de um sistema integrado tem o respeito mútuo como base e, consequentemente, foca em quão bem o sistema funciona, mudança que provavelmente resulta mais diálogo e menos deferência pura e simples.

Três importantes desenvolvimentos são observados.

Primeiramente, o surgimento do judicial comity a partir do comity of nations.

O comity of nations é um conceito legal e político. Um princípio. Significa “o respeito devido às leis e atos de outras nações em razão de sua qualidade de participante do sistema internacional - a presunção de reconhecimento que é algo mais que cortesia, porém menos que obrigação" (SLAUGHTER, 2004, p. 85-86).

As cortes têm invocado o princípio em diferentes contextos e com diferentes significados para justificar a deferência ao braço executivo da soberania nacional em decisões com possibilidade de impacto nas relações internacionais. Surge, com frequência, nos casos em que as cortes devam decidir qual a competência territorial mais adequada para produção da prova, minimizando deslocamentos e maximizando o conhecimento do juiz sobre a lei aplicável, e ao decidir sobre qual litígio deve seguir o seu curso, nos casos em que autor e réu invertem as suas posições processuais em dois ou mais países em torno da mesma causa de pedir. Assim, o judicial comity oferece um quadro e regras básicas para um diálogo global entre juízes no contexto de casos específicos (SLAUGHTER, 2004, p. 86-87, passim).

Para BREYER (2015, p. 92) as cortes devem cada vez mais levar em consideração as leis estrangeiras e domésticas em conjunto, como se constituintes de uma larga rede legal interconectada. Deste modo, o antigo conceito de comity assume um significado mais amplo. Atualmente, ao aplicá-lo, a Suprema Corte americana tem buscado interpretações da lei interna que permitam um trabalho harmônico em relação às leis estrangeiras, de tal modo que possam, juntas, atingir mais efetivamente os objetivos em comum.

O judicial comity tem quatro bases: a primeira é o respeito pelas cortes estrangeiras por serem cortes, mais do que por comporem um governo estrangeiro e, portanto, em razão de sua competência em resolver litígios e interpretar e aplicar a lei; segunda, o reconhecimento de que cortes em diferentes nações têm a sua parcela de casos a resolver, tanto como componentes de uma tarefa global (global task of judging) quanto como instrumentos de 
interesse em resolver controvérsias locais no âmbito doméstico do país respectivo; terceira, ênfase nos direitos individuais e no papel do judiciário na sua proteção; e, quarta, maior disposição em colidir com outras cortes, quando necessário, como uma parte inerente do exercício das funções judiciais como iguais em um empreendimento em comum (SLAUGHTER, 2004, p. 87).

No que tange à Suprema Corte americana, BREYER (2015, P. 92; 133) afirma que a abordagem do princípio do comity sofreu mutações. Partindo de uma ênfase mais formalobjetiva, de simplesmente evitar conflitos, para uma mais prática: a manutenção de trabalho cooperativo com as autoridades responsáveis pela aplicação da lei de diferentes nações, sendo crescente a necessidade judicial de informações sobre práticas, regras, leis e procedimentos judiciais e administrativos estrangeiros. Atualmente, comity significa algo mais: significa buscar interpretações que permitam trabalhar em harmonia com ordenamentos jurídicos estrangeiros, de tal modo que sejam mais efetivamente alcançados os objetivos comuns.

Com este raciocínio, Richard PoSNER, juiz do Tribunal Federal do Sétimo Circuito dos Estados Unidos, entendeu que as regras nacionais que estabelecem limites para a duplicação de litígios devem ser aplicadas também para litígios que se duplicam fora do território nacional, destacando que, ao invés de simplesmente se prestar deferência a uma abstrata noção de comity, as cortes devem exigir "certa quantia de carne para o esqueleto teórico", bem como insistir na explicitação de um risco atual para as relações bilaterais entre as nações envolvidas, sem o qual a corte está livre para processar o litígio de acordo com os melhores interesses da aplicação da justiça no caso concreto (apud SLAUGHTER, 2004, p. 89).

SLAUGHTER (2004, p. 89-91, passim) constata que o judicial comity se funda mais na deferência e menos na reciprocidade, sendo que diversamente do comity tradicional, há disposição também para assumir o conflito, quando necessário, bem como rejeita concepções "paroquiais" de que todos os conflitos devam ser resolvidos nas cortes nacionais e com as leis internas de cada país. A mudança no conceito implica o reconhecimento da existência de foros mais apropriados dentre aqueles possíveis. E mais: que tais foros devem ser identificados com base nas especificidades do caso concreto (interesses das partes, reconhecimento de necessidades dos litigantes individuais e o "fim" da justiça) mais do que em convenções entre soberanias estatais.

Cuida-se, na espécie, da aplicação do princípio da jurisdição razoável, componente dos princípios instrumentais do contencioso internacional privado, e que permite "a 
coordenação de soluções quanto à competência internacional dos tribunais domésticos em casos de conflitos e mesmo de exercício irrestrito de jurisdição pelo Estado”. Explica POLIDO (2013, p. 40-41) que "segundo este princípio, todo litígio privado pluriconectado somente deve ser adjudicado pelos tribunais que tenham razoável conexão com o objeto em disputa (portanto, a relação jurídica controvertida subjacente)". Com isso, no caso misto (ou pluriconectado) - aquele ligado a duas ou mais ordens jurídicas simultaneamente, no plano hipotético -, parte-se de um "vínculo razoável (i.é., de proximidade, de conexão)" para a definição da competência jurisdicional ${ }^{13}$.

O segundo desenvolvimento diz respeito à avaliação relativa aos juízes de outras nações.

Este desenvolvimento diz diretamente com os atributos de qualificação, independência, imparcialidade e eficiência dos juízes e do sistema judicial das nações.

Para SLAughter (2004, p. 91), a concepção de um sistema legal integrado tem duas características: os litigantes (e seus conflitos legais) se movem com relativa liberdade pelas fronteiras, podendo escolher um foro nacional em particular, e as cortes prestam deferência ou rejeitam este foro estrangeiro por razões de eficiência, justiça ou com base na finalidade da prestação jurisdicional, mais do que com fulcro na soberania estatal. SLAUGHTER nomeia tal prática como judges judging judges.

A presunção de identidade da função judicial desempenhada provoca o escrutínio pelas cortes de suas correspondentes em outras soberanias baseado nos mesmos critérios que aplicariam internamente em circunstâncias semelhantes, de modo que pequenas diferenças podem se tornar significativas, dependendo do caso. "Daí a necessidade não só de conhecimento, mas também de reconhecimento mútuos, os quais constituem, de alguma forma, a condição prévia de qualquer intercâmbio", afirmam ALLARD e GARAPON (2006, p. 27-28); e continuam: “e esta avaliação afecta todos os níveis: não só as decisões mais graves, mas também a eficácia das decisões ordinárias, não só os tribunais supremos, as instâncias superiores, mas também os "juízes de base"”, concluindo que "a metáfora do comércio

13 Cf., também, "Por jurisdição razoável, entende ser o princípio de que todo caso com elementos transfronteiriços deve ser julgado por um juiz que tenha razoável conexão com o objeto dos litígios, pois esses casos, em geral, estão ligados a mais de uma ordem jurídica e será preciso definir qual delas é competente. Não há uma instância internacional para resolver o problema da competência adequada, em vista da soberania de cada Estado em determinar sua jurisdição. No entanto, esse princípio deve servir para informar e determinar situações não previstas nos arts. 21 a 25 do CPC, sempre levando em conta a necessidade de se evitar a escolha de um foro arbitrário ou abusivo por meio da utilização do forum shopping” (ARAÚJO, 2019, p. 160). 
continua a aplicar-se plenamente neste caso, pois esta confiança não se institui por decreto, apenas pode ser conquistada ou 'inspirada'".

Decorrentemente, a assunção de que o sistema legal estrangeiro não é separado, mas, ao contrário, uma parte do espaço transnacional de litigância no qual as partes se deslocam livremente e escolhem diferentes cortes nacionais para resolver as suas disputas pode resultar - ao menos imediatamente - em um número maior de conflitos, os quais estarão a serviço de uma mais aprofundada cooperação a longo prazo.

\subsection{Judicial negotiation}

Outro desenvolvimento na temática da cooperação judicial em litígios transnacionais é a denominada judicial negotiation, prática desenvolvida nos países da tradição do common law em casos de falência, nos quais juízes se comunicam diretamente entre si, independentemente de tratados ou convenções internacionais, com o objetivo de garantir uma cooperação efetiva.

De acordo com SLAUGHTER (2004, p. 94-96), os governos têm deixado este assunto para as cortes e estas têm respondido ao desafio criando a sua própria disciplina para os casos. São acordos entre cortes, conhecidos como Cross-Border Insolvency Cooperation Protocols, cujo primeiro caso foi a negociação entre as cortes do Southern District of New York e a Justiça do Reino Unido, resultando em um minitratado order and protocol aprovado e adotado pelas duas cortes, indicando leis e procedimentos processuais a serem adotados na recuperação judicial, apontando administradores, responsáveis por extensas discussões e, por fim, estabelecendo procedimentos e responsabilidades pela liquidação, na década de 1990, da falida Maxwell Communications Corporation, uma companhia inglesa com mais de quatrocentas subsidiárias ao redor do mundo. A mesma experiência foi observada no caso Nakash, envolvendo EUA (de tradição da common law) e Israel (de tradição da civil law), merecendo destaque o preâmbulo do protocolo a estabelecer, dentre outros objetivos, a "honorabilidade... da integridade das cortes dos EUA e de Israel". Na ocasião, o juiz americano que aprovou o protocolo explicitamente mencionou a importância da "ponte" entre as cortes, de modo a permitir ambos os lados entender os objetivos do outro.

Observadores de tal espécie de cooperação enfatizam que ela floresceu na ausência de tratados, para fazer face à necessidade de as cortes lidarem com ativos globais sem que 
houvesse prévias orientações claras sobre como proceder, quer na legislação nacional quer na internacional.

\subsection{Meeting face to face}

A última das categorias de cooperação judicial internacional são os encontros de juízes (meeting face to face).

Os juízes estão, cada vez mais, encontrando-se diretamente, tanto os componentes dos tribunais constitucionais ou das mais altas cortes nacionais quanto os juízes atuantes nos graus iniciais de jurisdição (BREYER, 2015, p. 249).

Estes encontros são ora institucionalizados (organizados pelos próprios tribunais ou cortes), ora decorrentes de programas de estudos universitários (organizados por universidades ou faculdades de direito ao redor do mundo) ou mesmo por associações nacionais ou internacionais de magistrados.

SLAUGHTER (2004, p. 96-97) reporta encontros entre os componentes da Suprema Corte americana e magistrados de cortes da União Europeia, França, Alemanha, Inglaterra, Luxemburgo, Índia e México. No mesmo sentido, afirma que juízes de outras partes do mundo vêm consideravelmente institucionalizando tais intercâmbios. Por exemplo, juízes das cortes constitucionais da Europa ocidental, que desde a década de 1980 estão se encontrando a cada dois ou três anos.

A comissão de Veneza, criada em 1990, por exemplo, é o órgão do Conselho da Europa com competência consultiva em matéria constitucional. A comissão é composta por especialistas independentes, nomeados para mandatos de quatro anos pelos estados-membros. As sessões plenárias são realizadas com o intuito de aprovar pareceres e estudos e para promover a troca de informações sobre desenvolvimentos constitucionais. Além de representantes dos países europeus, participam da Comissão membros oriundos de Tribunais e Cortes Constitucionais de países de outras regiões, a exemplo do Brasil, membro pleno da Comissão (BRASIL, 2014).

Resultado de encontros como os acima elencados, foi criada a Organização das Supremas Cortes das Américas, em 1995, quando foi aprovada a Carta da organização, estabelecendo objetivos de promover e fortalecer a independência judicial e o Estado de Direito entre os membros, assim como o tratamento adequado da judiciário como função 
fundamental do Estado, objetivos a serem alcançados por meio de atividades bem como por meio de contato permanente entre os sistemas judiciários nacionais e sistemas educacionais e técnicos designados para promover a cooperação judicial no hemisfério. Recentemente, a organização foi encarregada de criar um centro de intercâmbio de informações sobre questões judiciais.

Em 21 de novembro de 2008, em Brasília, foi criada a organização Conferência das Jurisdições Constitucionais dos Países de Língua Portuguesa, mediante adesão de Angola, Brasil, Cabo Verbe, Guiné-Bissau, Moçambique, Portugal, São Tomé e Príncipe e Timor Leste. Seus estatutos foram aprovados em Lisboa, em maio de 2010, e o objetivo da congregação dos tribunais máximos de cada país é estabelecer rede de cooperação judiciária, jurisprudencial e científica para promover os direitos humanos, defender a democracia e a independência judicial da comunidade lusófona (CJCPLP, 2020).

BREYER (2015, p. 249), por seu turno, menciona o paradigmático Committee on International Judicial Relations, estabelecido pelo Judicial Conference of the United States, uma espécie de Conselho da Justiça Federal americano (Central Administrative Group of Federal Trial Court and Appellate Court Judges), o qual, com o apoio do Departamento de Estado americano, têm coordenado conferências, palestras e encontros nos Estados Unidos e no estrangeiro. Desde a sua criação, juízes americanos encontraram-se com juízes, procuradores ou promotores de justiça e administradores do poder judiciário da Albânia, Bangladesh, Brasil, Botsuana, Camboja, China, Colômbia, Equador, Gana, Indonésia, Irlanda, Libéria, Mauritânia, Namíbia, Qatar, Rússia, Ucrânia, Tunísia e dos Emirados Árabes Unidos, dentre outros países.

SLAUGHTER (2004, p. 98) refere-se, ainda, aos encontros menos formais, patrocinados por organizações não-governamentais e organizações tais como a London-based human rights organization - InterRights, a LawAsia e a ABA Central and Eastern European Law Initiative (CEELI). Faculdades de direito também têm desempenhado importante papel, destacando-se a New York University Law School's Center for International Studies and Institute of Judicial Administration, a Harvard Law School e a Yale Law School, que vêm realizando sucessivos seminários com a presença de juízes.

$\mathrm{Na}$ França, a Corte de Cassação estabelece relações com inúmeras Cortes Supremas estrangeiras e participa de redes internacionais de intercâmbios entre jurisdições. Recentemente, por exemplo, concluiu convenções de colaboração com a Suprema Corte 
Popular da China e com a Corte de Cassação da Tunísia. O objetivo, diz o Étude Annuelle da Cour de Cassation, "é favorecer o intercâmbio de pontos de vista sobre temas de interesse em comum (...). Consciente do enriquecimento que pode promover o direito comparado, a Alta Corte desenvolve, além disso, ferramentas de conhecimento sobre os direitos estrangeiros" (COUR DE CASSATION, 2017, p. 14).

Qual a finalidade destes cursos, encontros e seminários? Servem para a educação e para a formação continuada dos participantes. Igualmente, são oportunidades para fertilização cruzada (BREYER, 2015, p. 262, 267-268, 273, 274, passim). Por fim, são significativos na ampliação dos horizontes dos participantes (SLAUGHTER, 2004, p. 99).

BREYER (2015, p. 249) a partir de suas próprias experiências nestes intercâmbios, afirma que juristas americanos e estrangeiros descobriram ter mais em comum do que pensavam, pois confrontam os mesmos problemas e desempenham tarefas judiciais semelhantes. Slaughter (2004, p. 99), por sua vez, afirma que talvez o mais importante destes seminários e intercâmbios, é que "eles socializam seus membros como participantes de um empreendimento judicial comum". Esta consciência é de especial importância "para convencer os juízes a sustentar normas globais de independência judicial e integridade em países e nos momentos nos quais tais normas estejam sob ataque".

\section{Conclusão}

Como se afirmou no início deste texto, cada vez mais os juízes têm se articulado ao redor de problemas, casos e formações em comum. ALLARD e GARAPON (2006, p. 85-86) sublinham que estes "intercâmbios entre juízes provocam uma 'ruptura epistemológica na própria concepção do sistema de direito"”, afirmando que os juristas precisam ser preparados para o essa nova forma de diálogo, ou seja, que viajem, que tenham conhecimentos sobre outros direitos e culturas jurídicas, que sejam incentivados a acessar decisões estrangeiras.

Componentes de um emergente sistema legal global, desorganizado e complexo, com redes de trabalho horizontais e verticais, composta por juízes nacionais e internacionais, os magistrados passam a ser instados à adoção de uma postura ativa, de progressivos diálogo e cooperação com os seus pares e à associação com os seus homólogos nacionais e estrangeiros, numa perspectiva de rearticulação da função judicial no plano mundial, que passa a se estender para além das fronteiras. 
Na linha da exposição de SLAUGHTER (2004, passim), buscou-se abordar as diferentes categorias de interações judiciais que se vem constatando neste contexto: a fertilização cruzada, a construção de uma comunidade global de direitos humanos, o tratamento dos litígios privados internacionais e os encontros pessoais entre juízes ao redor do mundo.

A síntese deste conjunto mostra que os limites territoriais são cada vez mais transpostos e que embora cada litígio tenha o seu juiz natural, este magistrado compõe um conjunto maior, encarregado de um empreendimento comum, para o qual não está só.

\section{Bibliografia}

ALLARD, Julie; GARAPON, Antoine. Les juges dans la mondialisation - La nouvelle révolution du droit. Paris: Éditions du Seuil et La République des idées, 2005.

. Os juízes na mundialização - a nova revolução do direito. Trad. Rogério Alves. Lisboa: Instituto Piaget, 2006.

ARAÚJO, Nádia. Direito Internacional Privado - teoria e prática brasileira. 8. ed. rev. e atual. São Paulo: Thomson Reuters Brasil, 2019.

ARNULL, Anthony. European Union Law - A Very Short Introduction. Oxford: Oxford University Press, 2017.

BASSO. Maristela. Curso de Direito Internacional Privado. São Paulo: Atlas, 2009.

BREYER, Stephen. The court and the world-American Law and the New Global Realities. New York: Alfred A. Knopf, 2015.

BRASIL. Ministro Lewandowski assume Presidência da Subcomissão para a América Latina da Comissão de Veneza. Notícia 13.12.2014. Brasília. Disponível em $<$ https://stf.jusbrasil.com.br/noticias/157522326/ministro-lewandowski-assume-presidenciada-subcomissao-para-a-america-latina-da-comissao-de-veneza>. Acesso em 15.04.2020.

CASSESE, Sabino. Il Diritto Globale - Giustizia e democrazia oltre lo stato. Turino: Einaudi, 2009.

CASTELLS, Manuel. A sociedade em rede. $19^{\mathrm{a}}$ ed. rev. e atual. Rio de Janeiro/São Paulo: Paz \& Terra, 2018, vol. 1.

CJCPLP. Conferências das Jurisdições Constitucionais dos Países de Língua Portuguesa -O que é?. Disponível em <http: //cjcplp.org/cjcplp/>. Acesso em 15.04.2020.

COUR DE CASSATION. Le juge et la mondialisation dans la jurisprudence de la Cour de Cassation. Étude Annuelle 2017. Paris: La documentation Française, 2017.

GONÇALVES, Gláucio Ferreira Maciel. Tempo e direito. In: JAYME, Fernando Gonzaga; FARIA, Juliana Cordeiro de; LAUAR, Maira Terra (Coord.). Processo Civil Novas 
Tendências - em homenagem ao Ministro Sálvio de Figueiredo Teixeira. Belo Horizonte: Del Rey, 2011.

MILLS, Alex. Normative Individualism and Jurisdiction in Public and Private International Law: Toward a 'Cosmopolitan Sovereignty'?. Disponível em <papers.ssrn.com/sol3/papers.cfm?abstract_id=2055295>. Acesso em 20-01-2020.

PICARDI, Nicola. Le trasformazioni della giustizia nell'età della globalizzazione. Rivista di Diritto Processuale. Pádua, Vol. 67, nº 5, 2012, p. 1153-1165.

POLIDO. Fabrício Bertini Pasquot. Direito Processual Internacional e o Contencioso Internacional Privado. Curitiba: Juruá, 2013.

REZEK, Francisco. Direito Internacional Público - curso elementar. 15. ed. rev. e atual. São Paulo: Saraiva, 2014.

SLAUGHTER, Anne-Marie. A new world order. Princeton: Princeton University Press, 2004.

TARUFFO, Michele. Ensaios sobre o processo civil - escritos sobre processo e justiça civil. Porto Alegre: Livraria do advogado, 2017.

THEODORO JÚNIOR, Humberto; NUNES, Dierle; BAHIA, Alexandre Melo Franco; PEDRON, Flávio Quinaud. Novo CPC - Fundamentos e sistematização. 3. ed. rev., atual. e ampl. Rio de Janeiro: Forense, 2016.

WALDRON, Jeremy. "Partly Laws Common to All Mankind" - Foreign Law in American Courts. New Haven: Yale University, 2012. 